\title{
AVALIAÇÃO DE UM ATERRO CONTROLADO DE RESÍDUOS SÓLIDOS URBANOS ATRAVÉS DO MÉTODO DE IQR-VALAS
}

\author{
Silvana De Jesus Galdino ${ }^{1}$
}

Carlos Humberto Martins ${ }^{2}$

Eraldo Schunk Silva ${ }^{3}$

\begin{abstract}
RESUMO
Adotar medidas para minimizar os impactos ambientais decorrentes de deficiências na gestão e gerenciamento dos resíduos, tornou-se problema na maioria das cidades brasileiras. Isso está diretamente relacionado à falta de infraestrutura adequada, equipe técnica qualificada, equipamentos e escassez de recursos necessários. Aproximadamente $41,74 \%$ dos municípios brasileiros destinam os resíduos sólidos em locais inadequados e 58,26\% em locais adequados (ABRELPE, 2013). Considerando que, como em outros lugares, essa situação pode ser verificada em pequenos municípios, a pesquisa teve como objetivo avaliar as condições de disposição final dos resíduos sólidos urbanos no aterro controlado do município de MamborêPR. A pesquisa envolveu análise teórica, levantamento de dados a campo, registro fotográfico, visitas in loco e análise qualitativa dos dados através do Índice de Qualidade de Aterros de Resíduos (IQR-Valas), desenvolvido pela Companhia de Tecnologia de Saneamento Ambiental (CETESB, 2006). A avaliação das condições atuais de disposição final dos resíduos sólidos pode ajudar o poder público na tomada de decisões que contemplam ações de gestão integrada dos resíduos gerados no município. No que diz respeito às condições locacionais, $80 \%$ dos subitens avaliados foram considerados em condições adequadas e $20 \%$ considerados como inadequados ou insuficientes. Todavia, $85 \%$ dos subitens avaliados no item infraestrutura implantada no local foram considerados inadequados ou inexistentes, sendo $15 \% \mathrm{em}$ condições adequadas. Os subitens avaliados no item condições operacionais do aterro, $66,6 \%$ foram considerados inadequados ou inexistentes e apenas $33,4 \%$ dos subitens foram considerados em condições adequadas. $O$ aterro foi classificado como em condições inadequadas em vários aspectos, totalizando uma pontuação de 5.4 .
\end{abstract}

Palavras-chave: Aterro, IQR-Valas, gerenciamento, resíduos sólidos, disposição final

\section{EVALUATION OF A CONTROLLED LANDFILL OF MUNICIPAL SOLID WASTE THROUGH THE TRENCHES IQR-METHOD}

\footnotetext{
${ }^{1}$ Bacharel em Geografia, Mestre em Engenharia Urbana/Universidade Estadual de MaringáUEM, PR

E-mail silgaldino@outlook.com

${ }^{2}$ Prof $^{\circ}$, Dr., Departamento de Engenharia Civil/Universidade Estadual de Maringá-UEM, PR

E-mail chmartins2008@gmail.com

${ }^{3}$ Prof $^{\circ}$, Dr,. Departamento de Estatística/Universidade Estadual de Maringá-UEM,PR

E-mail eraldoschunks@gmail.com
} 


\title{
Periódica Eletrânica

\begin{abstract}
Take measures to minimize the environmental impacts of weaknesses in the management and waste management, it has become a problem in most cities. This is directly related to lack of adequate infrastructure, skilled technical staff, equipment and shortage of necessary resources. Approximately 41,74\% Brasil counties aimed municipal solid waste in inappropriate places and $58,26 \%$ in appropriate places (ABRELPE, 2013). Whereas, as elsewhere, this situation can be seen in small counties, the research aimed to evaluate the conditions of final disposal of municipal solid waste on the site the landfill of the city of Mamborê-PR. The research involved theoretical analysis, field data collection, photographic documentation, site visits and qualitative analysis through Quality Waste landfills Index (IQR-Valas), developed by the Environmental Sanitation Technology Company (CETESB, 2006). The assessment of current conditions of final disposal of solid waste can help the government in making decisions that include integrated management actions of waste generated in the county. With regard to locational conditions, $80 \%$ of the assessed sub-items were considered under appropriate conditions and $20 \%$ considered as inadequate or insufficient. However, $85 \%$ of sub-items evaluated in the item infrastructure deployed at the site, were considered inadequate or non-existent, $15 \%$ being in appropriate conditions. The sub-items evaluated in the item operating conditions of the landfill, $66,6 \%$ were considered inadequate or non-existent and only $33,4 \%$ of sub-items were considered in appropriate conditions. The landfill was rated in poor condition in many respects, totaling a 5.4 score.
\end{abstract}

Key words: Landfill, IQR-Valas, management, solid waste, and final disposal.

\section{EVALUACIÓN DE UN VERTEDERO DE RESIDUOS SÓLIDOS URBANOS CONTROLADO MEDIANTE MÉTODO IQR- TRINCHERAS}

\section{RESUMEN}

Tome medidas para minimizar los impactos ambientales derivados de las deficiencias en la gestión y manejo de residuos, se ha convertido en un problema en la mayoría de las ciudades. Esto está directamente relacionado con la falta de infraestructura adecuada, personal técnico especializado, equipos y escasez de recursos necesarios. Aproximadamente el $41,74 \%$ de los municipios brasileños intención de residuos sólidos en lugares inadecuados y 58,26\% en los lugares apropiados (ABRELPE, 2013). Considerando que, por otra parte, esta situación se puede ver en los municipios pequeños, la investigación tuvo como objetivo evaluar las condiciones de disposición final de los vertederos de residuos sólidos urbanos en el municipio de Mambore-PR. En la investigación participaron análisis teórico, campo de recopilación de datos, registro fotográfico, loco cualitativa y el análisis de las visitas de los datos a través de la calidad de los residuos Índice Vertederos (RIC-Valas), desarrollado por la Compañía de Tecnología de Saneamiento Ambiental (CETESB, 2006 ). La evaluación de las condiciones actuales de la disposición final de los residuos sólidos puede ayudar al gobierno en la toma de decisiones que incluyen acciones de gestión de los residuos generados en el municipio integrados. Con respecto a las condiciones de localización, el $80 \%$ de la sub evaluado ha considerado las circunstancias apropiadas y el $20 \%$ se consideran como inadecuados o insuficientes. Sin embargo, el $85 \%$ de los subtemas evaluados en la infraestructura material desplegado en el lugar se consideraron inadecuadas o inexistentes, el 15\% en condiciones adecuadas. Los subtemas evaluados en las condiciones de funcionamiento tema del relleno sanitario, el 66,6\% se consideraron inadecuadas o inexistentes y sólo el 33,4\% de los subtemas fueron considerados en las condiciones apropiadas. El vertedero fue calificado en mal estado, en muchos aspectos, por un total de una puntuación de 5,4.

Palabras clave: Vertedero, IQR-Valas, administración, disposición de residuos sólidos 


\section{INTRODUÇÃO}

Um dos maiores desafios da sociedade tem sido encontrar soluções ambientalmente adequadas para disposição final dos resíduos sólidos urbanos, em especial os resíduos domiciliares, os quais têm aumentado consideravelmente devido ao crescimento populacional, modo de produção e deficiências no sistema de gerenciamento e gestão integrada.

Com base em dados estatísticos disponibilizados pela Associação Brasileira de Empresas de Limpeza Pública e Resíduos Especiais - ABRELPE (2013), a geração de resíduos sólidos urbanos (RSU) no Brasil é de 209.280 t/dia, com acréscimo de 4,1\%, do ano de 2012 para o ano de 2013, índice superior à taxa de crescimento populacional urbano no país no período, que foi de $3,7 \%$. Dentre a taxa total de resíduos sólidos gerados, foram coletados $189.219 \mathrm{t} / \mathrm{dia}$, entretanto, $20.000 \mathrm{t} /$ dia deixaram de ser coletados no Brasil. Aproximadamente $41,74 \%$ municípios brasileiros destinam os resíduos sólidos urbanos em locais inadequados e $58,26 \%$ em locais adequados (ABRELPE, 2013).

De acordo com Besen et al. (2010), as deficiências na gestão e gerenciamento, bem como a disposição final inadequada dos resíduos sólidos urbanos causam impactos socioambientais, tais como, degradação do solo, comprometimento de corpos d' água e mananciais, intensificação de enchentes, poluição do ar e proliferação de vetores e catação em condições insalubres.

$\mathrm{Na}$ busca de um ambiente economicamente, socialmente e ambientalmente equilibrado, surgiu a Política Nacional de Resíduos Sólidos Lei 12.3005/2010 que reúne princípios, objetivos, instrumentos e diretrizes para gestão dos resíduos, dentre as medidas está a eliminação dos lixões e disposição final ambientalmente segura. Todavia, com as dificuldades financeiras e de planejamento, a maioria das prefeituras municipais não se adequou a Lei 12.305 da Política Nacional de Resíduos Sólidos, principalmente 


\section{Periódica Eletrônica

no que diz respeito à irradicação dos lixões à céu aberto e construção de aterros sanitários.

De acordo com o Conselho Nacional do Meio Ambiente, Resolução CONAMA n001/1986, a disposição final adequada dos resíduos gerados corresponde à distribuição ordenada dos rejeitos em aterros de acordo com normas operacionais para evitar possíveis danos ou riscos à saúde pública, segurança e impactos ambientais adversos. Dentre as formas de disposição final estão os aterros sanitários, aterros controlados e os lixões.

Para Bidone e Povinelli (1999), o aterro sanitário é um processo ou método utilizado para a disposição final de resíduos sólidos urbanos no solo que utiliza a impermeabilização de base, de acordo com critérios de engenharia e normas operacionais específicas, o qual permite o confinamento seguro dos resíduos e o controle da poluição ambiental e também evita danos ou riscos a saúde pública. Esta forma de disposição final de resíduos envolve sistema de drenagem de águas pluviais, sistema de drenagem para coleta e tratamento de lixiviados, drenagem e queima dos gases gerados durante o processo de bioestabilização da matéria orgânica e adequada impermeabilização do solo antes da disposição inicial de resíduos no solo.

A disposição dos resíduos sólidos em aterros controlados é uma técnica de disposição final que minimiza os impactos ambientais e de saúde pública, utilizando-se de alguns princípios de engenharia, porém não dispõe de impermeabilização de base e nem sistema de tratamento de lixiviado, sendo considerado bastante inferior ao aterro sanitário (Consoni et al., 2010). Já a disposição final de resíduos sólidos em lixões, vazadouros ou a céu aberto é considerado uma técnica totalmente inadequada de descarga sob o solo, sem medida de proteção ao meio ambiente, a saúde e a segurança.

Quanto à operação e manutenção do aterro sanitário em valas, devese considerar a elaboração do projeto e implantação do aterro sanitário (Neto, 2010). Todavia, faz-se necessário o gerenciamento adequado dos resíduos sólidos urbanos do município como um todo, uma vez que à frequência e o horário de coleta, o tipo de equipamento empregado, a existência de coleta 
diferenciada, entre outros fatores, irão influenciar diretamente no índice de qualidade do aterro.

Albertin et al. (2010), destaca que os problemas referentes a gestão inadequada dos resíduos não é somente em grandes centros urbanos, mas também em cidades de médio e pequeno porte que mesmo produzindo menos resíduos sofrem com a degradação ambiental e social.

Com base em pesquisas realizadas pela CETESB (2006), os municípios de pequeno porte encontram dificuldades quanto à gestão e gerenciamento adequados dos resíduos devido a descontinuidade administrativa, escassez de recursos financeiros e equipamentos para operação. Diante deste contexto, a pesquisa teve por objetivo avaliar e analisar a situação atual de disposição final dos resíduos sólidos no aterro de Mamborê -PR através da observação direta, visitas sistemáticas com o intuito de verificar in loco as características do local, infraestrutura e condições operacionais.

Para contribuir na avaliação das condições de disposição final dos resíduos sólidos no aterro controlado do município foi utilizado o método desenvolvido pela Companhia de Tecnologia de Saneamento Ambiental de São Paulo (CETESB, 2006), por meio do IQR (Índice de Qualidade de AterrosValas), que consiste na aplicação do questionário padronizado, "check list". Por meio da avaliação das condições atuais de disposição final dos resíduos sólidos, espera-se contribuir com o poder público na tomada de decisões que contemplam ações de gestão integrada.

\section{MATERIAIS E MÉTODO}

Esta pesquisa foi realizada no município de Mamborê localizado na Mesorregião Centro-Ocidental Paranaense (IPARDES, 2011). O município faz parte da Microrregião Homogênea 286 e pertence à COMCAM - Comunidade dos Municípios da Região de Campo Mourão limitando-se com Campo Mourão e Farol ao Norte, com Boa Esperança e Juranda a Oeste, com Campina da Lagoa e Nova Cantú ao Sul e com Luiziana a Leste (Figura 1). 
Figura 1: Mamborê-PR no contexto da Mesorregião Centro-Ocidental Paranaense

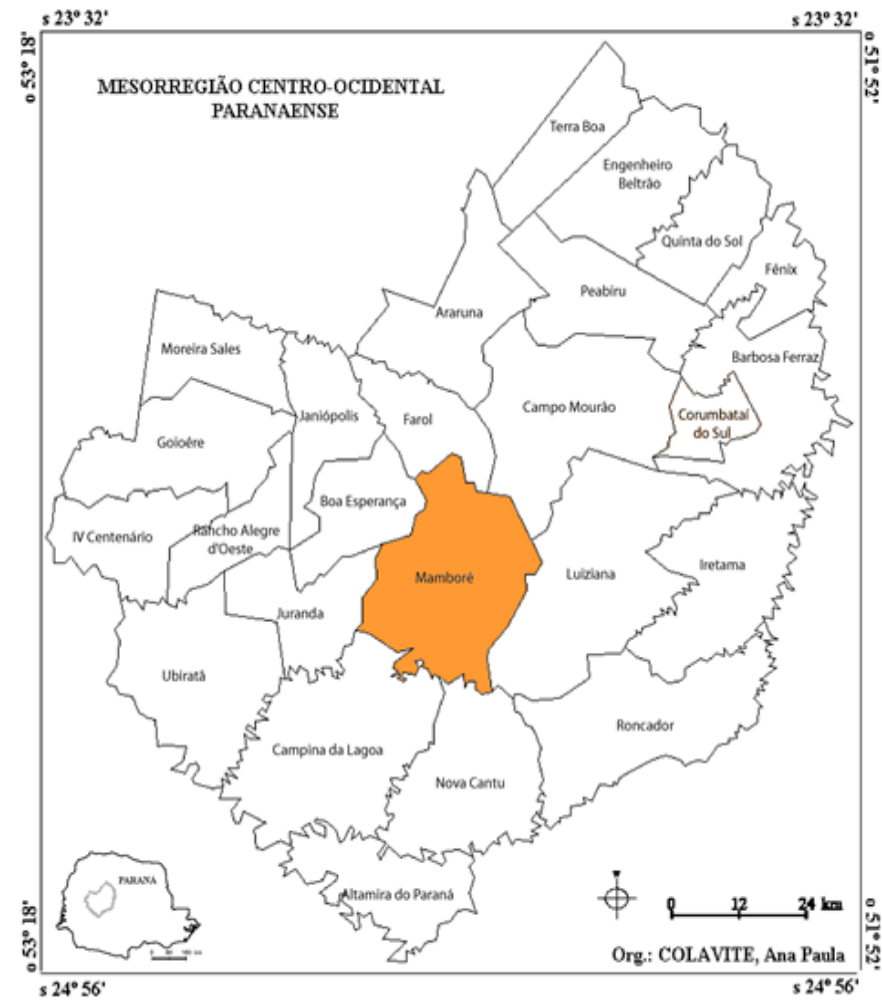

Fonte: Adaptado de IPARDES, 2011.

O município de Mamborê ocupa aproximadamente $788,062 \mathrm{~km}^{2}$ de área no terceiro planalto paranaense, entre as coordenadas de $24^{\circ} 17^{\prime} 30^{\prime \prime}$ Sul e, $52^{\circ} 31^{\prime} 10^{\prime \prime}$ a Oeste, com $980 \mathrm{~m}$ de altitude. O clima do município é do tipo Cfa ou Subtropical Úmido, sendo a média pluviométrica anual de $1.500 \mathrm{~mm}$ e média de temperatura de $20^{\circ} \mathrm{C}$. Possui uma população de 13.961 habitantes, destes 8.984 residem na área urbana, de acordo com o Instituto Brasileiro de Geografia e Estatística (IBGE, 2010).

\section{METODOLOGIA}

A avaliação das condições de deposição final dos resíduos sólidos no aterro seguiu o método desenvolvido pela Companhia de Tecnologia de Saneamento Ambiental de São Paulo (CETESB, 2006), por meio do IQR (Índice de Qualidade de Aterros - Valas). Este método consiste na aplicação de um questionário padronizado (check list) dividido em três partes, de acordo 
com os aspectos a serem avaliados, sendo o preenchimento realizado através de visitas in loco, registro fotográfico, histórico da destinação final dos resíduos sólidos e observação direta do local. São consideradas informações sobre: as características do local, a infraestrutura implantada no local e as condições operacionais.

Cada etapa do questionário apresenta um subtotal, denominados SUB1, SUB2 e SUB3, sendo que a soma dos 3 subtotais atingem um total máximo de 100 pontos. Usando-se a equação que determina o IQR-Índice de Qualidade de Aterros de Resíduos e o enquadramento das instalações de destinação final é possível determinar as condições de disposição final dos RSU em inadequadas (I), controladas (C) ou adequadas (A). EQ 1: IQR = $(\mathrm{SUB} 1+\mathrm{SUB} 2+\mathrm{SUB3}) / 10$.

\section{RESULTADOS E DISCUSSÕES}

Até o ano de 2006, o município disponha os resíduos sólidos urbanos em lixão a céu aberto, localizado no acesso da antiga estrada para Campina da Lagoa-PR, no lote no 032 com área de $32.000 m^{2}$, próximo ao perímetro urbano. Atualmente é utilizado como depósito de entulhos proveniente de podas, capinas, varrições e resíduos de construção civil, sem nenhum tipo de tratamento ou reaproveitamento.

Na Figura 2, é possível perceber a disposição dos resíduos de podas, varrições e capinas juntamente com materiais recicláveis domésticos e comerciais, e resíduos de construção civil (RCC). 
Figura 2: Antigo lixão sendo utilizado como depósito de entulhos

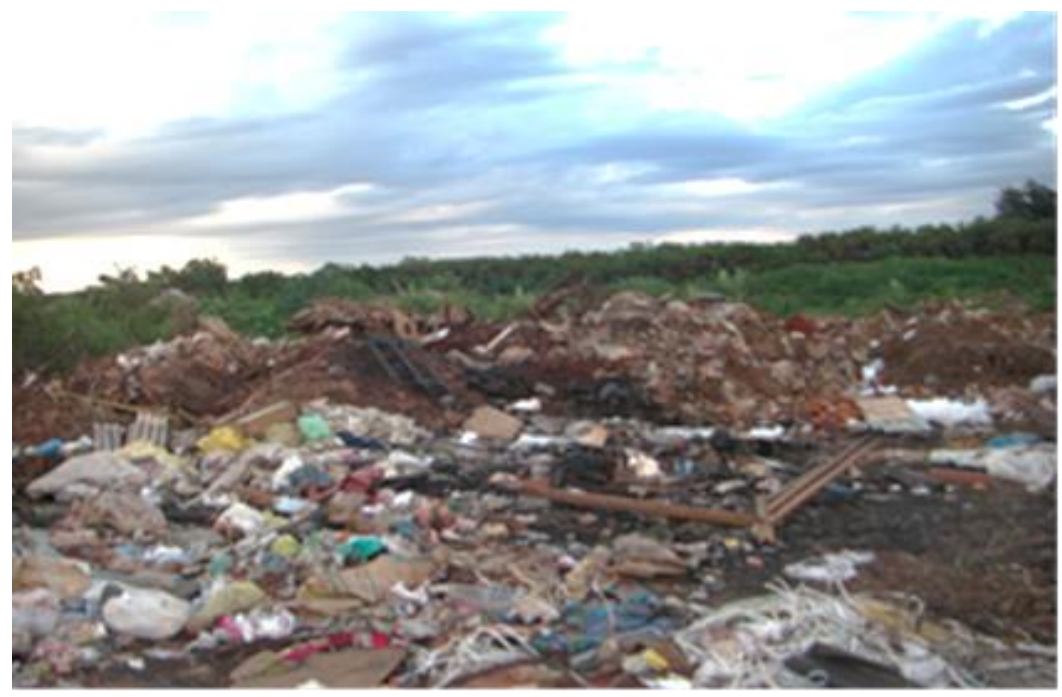

Fonte: Acervo pessoal

Os resíduos são dispostos diretamente no solo sem nenhum tipo de segregação, atraindo catadores de materiais recicláveis, famílias de baixa renda, devido a presença de materiais recicláveis, madeiras que podem ser reutilizadas em construções. Todavia, esses materiais são coletados por esses indivíduos, sem levar em consideração os riscos à saúde, por estarem junto à resíduos contaminantes.

Após 2006, o município começou a dispor os resíduos em aterro controlado, situado na estrada de acesso ao Patrimônio Guarani a $4 \mathrm{~km}$ da área urbana (Figura 3), lote 074 1-A, gleba nํ 05, Colônia Goio-Bang, Bacia do Rio Piquiri, em local permitido, licenciado pelo IAP, com isolamento visual razoável a ruim, e área de $20.000 \mathrm{~m}^{2}$, com projeção para deposição de resíduos até 2016.

Embora o local tenha sido licenciado pelo Instituto Ambiental do Paraná (IAP) em 2006, com a PNRS, Lei 12.305/2010 o município encontra certa dificuldade em renovar a Licença Ambiental (LA), pois o mesmo não atende a todos os critérios previstos pela lei, como infraestrutura e condições operacionais adequadas. Diante disso, o município terá que se adequar a Lei 12.305/2010 e gerenciar os resíduos produzidos de maneira consorciada com outros municípios da região, tendo em vista a disposição final em aterro sanitário somente dos rejeitos. 
Segundo o órgão gestor responsável pelo gerenciamento dos resíduos sólidos encaminhados ao aterro, o município de Mamborê-PR têm como alternativas, transformar o local em aterro sanitário ou aderir ao consórcio intermunicipal. Entretanto, adotar a segunda alternativa, de acordo com órgão gestor seria complicado, pois o município não tem suporte financeiro suficiente para encaminhar os resíduos para fora do município. As despesas com deslocamento, infraestrutura, transporte e mão de obra seria incompatíveis com as verbas destinadas ao setor.

\section{Características Locacionais}

De acordo com a Tabela 1 referente ao item características do local, mostra que alguns itens são inadequados, pois não atendem o exigido pela metodologia aplicada.

Tabela 1. Índice de qualidade de aterros de resíduos- IQR, pontuação referente. Item: Características do local

\begin{tabular}{|c|c|c|c|}
\hline Subitem & Condições & Pontos & Peso \\
\hline \multirow[t]{2}{*}{ Capacidade de suporte do solo } & Adequada & 5 & \multirow[t]{2}{*}{5} \\
\hline & Inadequada & 0 & \\
\hline \multirow[t]{2}{*}{ Proximidade de núcleos urbanos } & Longe $>500$ & 5 & \multirow[t]{2}{*}{5} \\
\hline & Próximo & 0 & \\
\hline \multirow[t]{2}{*}{ Proximidade dos corpos de água } & Longe $>200$ & 3 & \multirow[t]{2}{*}{3} \\
\hline & Próximo & 0 & \\
\hline \multirow[t]{3}{*}{ Profundidade do Lençol freático } & Maior de $3 \mathrm{~m}$ & 4 & \multirow[t]{3}{*}{4} \\
\hline & De 1 a 3 m & 2 & \\
\hline & De 0 a $3 \mathrm{~m}$ & 0 & \\
\hline \multirow[t]{3}{*}{ Permeabilidade do solo } & Baixa & 5 & \multirow[t]{3}{*}{5} \\
\hline & Média & 2 & \\
\hline & Alta & 0 & \\
\hline \multirow{3}{*}{$\begin{array}{l}\text { Disponibilidade de material para } \\
\text { recobrimento }\end{array}$} & Suficiente & 4 & \multirow[t]{3}{*}{4} \\
\hline & Insuficiente & 2 & \\
\hline & Nenhuma & 0 & \\
\hline \multirow[t]{2}{*}{ Qualidade do material para recobrimento } & Boa & 2 & \multirow[t]{2}{*}{2} \\
\hline & Ruim & 0 & \\
\hline \multirow{3}{*}{$\begin{array}{l}\text { Condições do sistema viário, trânsito e } \\
\text { acesso }\end{array}$} & Boas & 3 & \multirow[t]{3}{*}{0} \\
\hline & Regulares & 2 & \\
\hline & Ruins & 0 & \\
\hline \multirow[t]{2}{*}{ Isolamento visual da vizinhança } & Bom & 4 & \multirow[t]{2}{*}{0} \\
\hline & Ruim & 0 & \\
\hline \multirow[t]{2}{*}{ Legalidade de Localização } & Local permitido & 5 & \multirow[t]{2}{*}{5} \\
\hline & Local proibido & 0 & \\
\hline \multicolumn{2}{|l|}{ Subtotal máximo } & 40 & 33 \\
\hline
\end{tabular}

Fonte: CETESB,2006 
Quanto às características do local, o aterro apresenta capacidade de suporte do solo adequada, longe de núcleos habitacionais. O corpo de água mais próximo encontra-se localizado a aproximadamente 350 metros, com lençol freático em profundidade superior a $3 \mathrm{~m}$ em relação à base da vala, solo com baixa permeabilidade e topografia classificada como plana a levemente ondulada. Tais itens citados atendem aos critérios locacionais de implantação de aterro de resíduos sólidos urbanos de acordo com as normas da NBR ABNT/1984, sendo o subitem de maior pontuação na avaliação do índice de qualidade de aterro de resíduos, IQR-Valas.

O município apresenta declividades variando entre 1 e $45 \%$, com solos divididos da seguinte forma: latossolo roxo, $65 \%$; latossolo vermelho escuro, $13 \%$;terra roxa estruturada, $12 \%$ e podzólico vermelho-amarelo, $5 \%$, outros, $5 \%$ (EMBRAPA, 1999). Devido à predominância do latossolo roxo que se apresenta de forma profunda, resulta em adequada capacidade de suporte e baixa permeabilidade (PGRS, 2009).

Através de observações diretas e periódicas do local, constatou-se que, a disponibilidade de material para recobrimento dos resíduos depositados nas valas do aterro é considerada suficiente, sendo a qualidade do material para recobrimento considerado bom. No entanto, o manejo do solo disposto ao lado das valas não ocorre adequadamente, contribuindo para disposição dos resíduos ao relento. Isso está diretamente relacionado à ausência de equipamentos em certos períodos do ano para fazer o recobrimento e necessidade de abertura de novas valas para atender a demanda.

Quanto às condições do sistema viário, trânsito e acesso à área foi considerado inadequado devido à ausência de cascalhamento e manutenção, dificultando o deslocamento e acesso de maquinários e frente de trabalho ao aterro em períodos longos de chuva.

No que se refere ao isolamento da vizinhança, este não se encontra totalmente adequado, pois há presença de vegetação (eucaliptos) somente em um dos lados da área do aterro, em locais onde foi feito o reflorestamento. Todavia, a localização do aterro está de acordo com o zoneamento municipal e 
possui licença de funcionamento do órgão ambiental (IAP) desde a sua implantação, em 2006.

\section{Infraestrutura Implantada}

Construído em 2006, o aterro possui sistema de drenagem para lixiviados, sistema de drenagem das águas superficiais, bacia para captação do escoamento das águas pluviais e cerca com arrame farpado em todo o perímetro da área. Entretanto, o aterro não apresenta sistema de captação dos gases formados pela decomposição da matéria orgânica.

$\mathrm{Na}$ Tabela 2 é possível perceber as condições de infraestrutura implantada no local e o peso referente a cada subitem.

Tabela 2. Índice de qualidade de aterros de resíduos- IQR, pontuação referente. Item: Infraestrutura implantada

\begin{tabular}{|c|c|c|c|}
\hline Subitem & Condições & Pontos & Peso \\
\hline \multirow{2}{*}{ Cercamento da área } & Sim & 2 & \multirow[t]{2}{*}{2} \\
\hline & Não & 0 & \\
\hline \multirow[t]{2}{*}{ Vida útil das valas } & Suficiente & 6 & \multirow[t]{2}{*}{0} \\
\hline & Insuficiente & 0 & \\
\hline \multirow[t]{2}{*}{ Dimensões das valas } & Adequada & 6 & \multirow[t]{2}{*}{0} \\
\hline & Inadequada & 0 & \\
\hline \multirow{3}{*}{$\begin{array}{l}\text { Drenagem das águas pluviais } \\
\text { definitivas }\end{array}$} & Suficiente & 4 & \multirow[t]{3}{*}{2} \\
\hline & Insuficiente & 2 & \\
\hline & Inexistente & 0 & \\
\hline \multirow{3}{*}{$\begin{array}{l}\text { Drenagem das águas pluviais } \\
\text { provisórias }\end{array}$} & Suficiente & 2 & \multirow[t]{3}{*}{1} \\
\hline & Insuficiente & 1 & \\
\hline & Inexistente & 0 & \\
\hline \multirow[t]{2}{*}{ Acesso a frente de trabalho } & Bom & 3 & \multirow[t]{2}{*}{0} \\
\hline & Ruim & 0 & \\
\hline \multirow[t]{3}{*}{ Atendimento a estipulação de projeto } & Sim & 2 & \multirow[t]{3}{*}{1} \\
\hline & Parcialmente & 1 & \\
\hline & Não & 0 & \\
\hline \multicolumn{2}{|l|}{ Subtotal máximo } & 25 & 6 \\
\hline
\end{tabular}

Fonte: CETESB,2006

Observa-se que, alguns procedimentos preventivos presentes no projeto de aterro para o município de Mamborê-PR não são executados corretamente, ou seja, o atendimento a estipulação de projeto ocorre de maneira parcial, tornando-se fonte potencial de contaminação do ar, águas superficiais e subterrâneas e do solo, consequentemente, podendo comprometer a qualidade de vida do ser humano. 
Na Figura 3, percebe-se a ausência de manutenção da cerca que margeia o aterro, com presença de resíduos dispostos ao relento.

Figura 3: Cercamento deteriorado com presença de resíduos

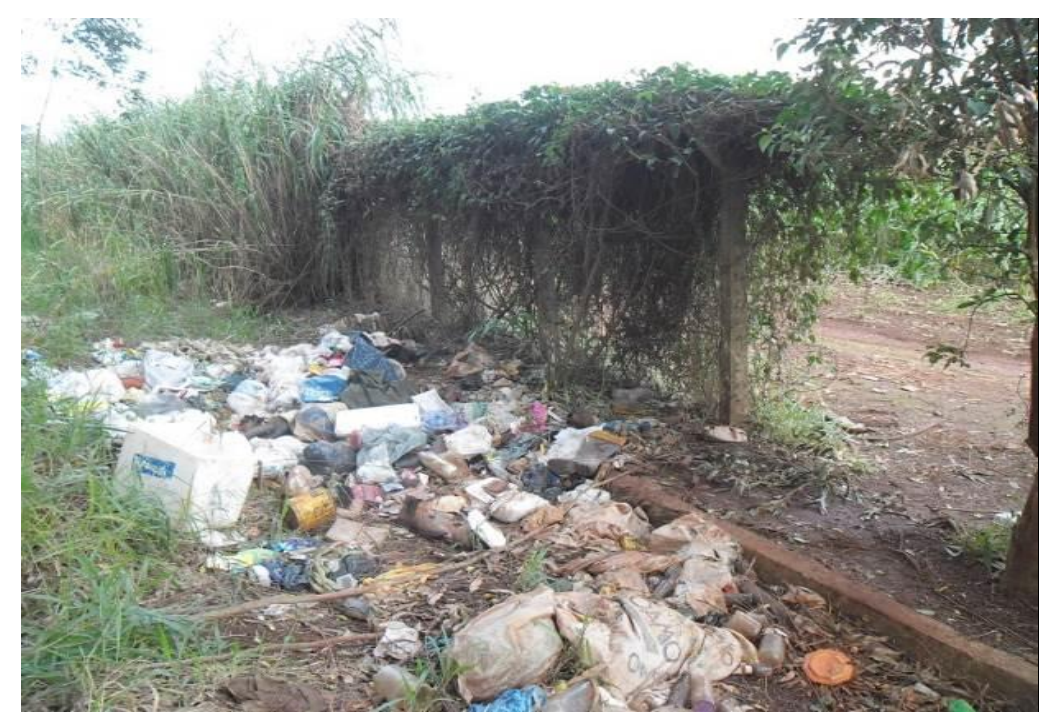

Fonte: Acervo pessoal

De acordo com diagnóstico direto do local, o funcionamento da drenagem pluvial definitiva e provisória do aterro é considerado insuficiente devido à falta de manutenção, presença de vegetação rasteira e resíduos no sistema de drenagem (Figura 4), dificultando o escoamento das águas superficiais e formando fina camada de água em períodos mais chuvosos.

Figura 4: Vegetação no sistema drenagem e acúmulo d'água

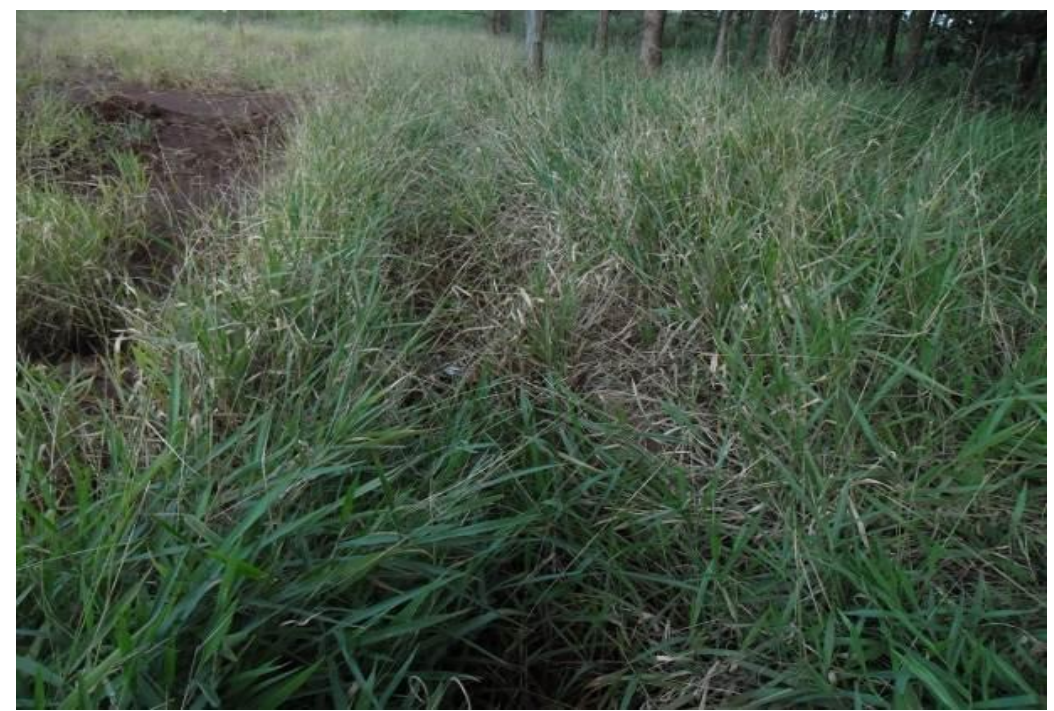

Fonte: Acervo pessoal 
O sistema de drenagem de águas pluviais, quando projetado de maneira adequada tem a finalidade de evitar a entrada descontrolada de água nas trincheiras, pois aumenta o volume de lixiviado e gera erosão, que pode causar a destruição da camada de cobertura dos resíduos e dos taludes.

Quanto a projeção das valas estipuladas no projeto, ocorre de maneira parcial e em alguns casos, são abertas sem levar em consideração as medidas exatas de projeto. Possui grande quantidade de materiais recicláveis que poderiam ser destinados a Associação de Catadores de Materiais Recicláveis do município.

De acordo com órgão gestor, a instalação de uma vala, dentro das normas técnicas tem um custo aproximado de $R \$ 70.000,00$ e vida útil em torno de 5 meses, considerando o atual ritmo de coleta realizado no município, entretanto, caso haja uma organização do sistema de coleta seletiva e os materiais recicláveis deixem de serem encaminhados ao aterro, a vida útil de cada vala pode chegar a 14 meses.

$\mathrm{Na}$ Figura 5, percebe-se a abertura da vala para disposição final dos resíduos da coleta convencional do município. A abertura da vala é realizada pela prefeitura do município, com uma retroescavadeira, em seguida uma empresa contratada, realiza o processo de instalação de sistema de drenagem para lixiviados e impermeabilização com geomembrana de polietileno de alta densidade (PEAD) de $2 \mathrm{~mm}$. 
Figura 5: Abertura da vala e instalação de drenagem de lixiviados

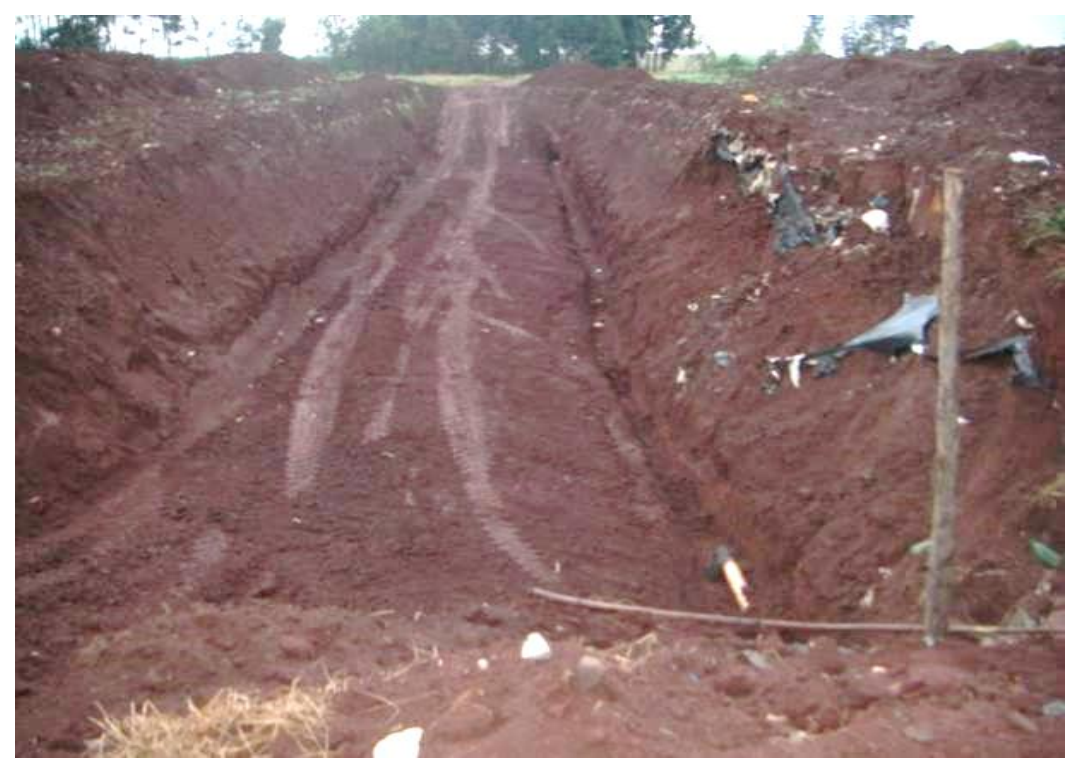

Fonte: Acervo pessoal

A necessidade de implantação de sistema de impermeabilização das bases e laterais das trincheiras depende da profundidade em que se encontra 0 lençol freático e da capacidade de infiltração de líquidos no solo. Neste caso, solos com baixa capacidade de infiltração de líquidos apresentam maior potencial para serem utilizados como camadas de impermeabilização, entretanto isso requer estudos detalhados das características geológicas do solo local.

Para o órgão gestor, a impermeabilização da vala tem por finalidade, atender as novas exigências dos órgãos ambientais e proteger o solo e as águas subterrâneas da contaminação por lixiviados, decorrentes do processo de decomposição da matéria orgânica (Figura 6). 


\section{Figura 6: Impermeabilização da base do aterro com geomembrana}

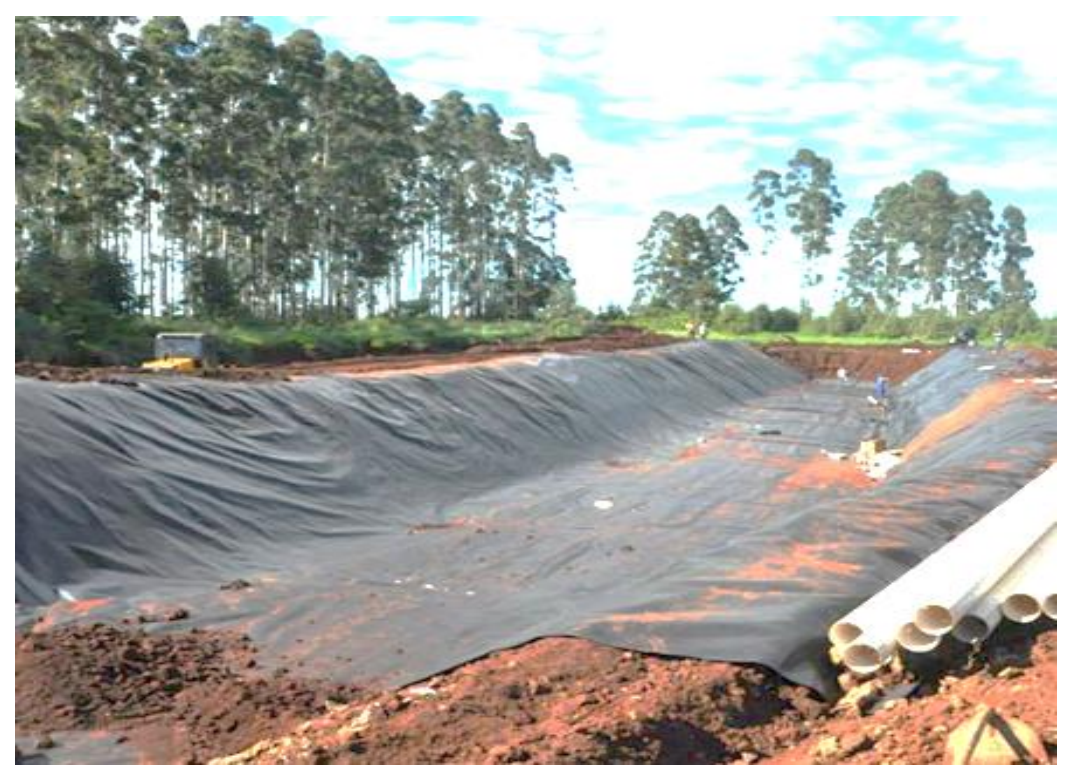

Fonte: Acervo pessoal

Também é adotado um sistema de recirculação de lixiviados, ou seja, um sistema de tratamento alternativo em que o líquido é utilizado no próprio aterro para acelerar o processo de decomposição da matéria orgânica. Utilizouse deste método devido à pequena quantidade de lixiviados gerados durante o processo, baixa permeabilidade do solo e a profundidade do lençol freático.

Com o levantamento de dados a campo e prefeitura de Mamborê -PR, foi constatado que a área de disposição final de resíduos sólidos do município encontra-se totalmente cercada de arrame farpado, com cortina vegetal de eucaliptos em apenas uma parcela da área (Figura 7). 
Figura 7: Resíduos expostos e cortina vegetal em apenas um lado do aterro

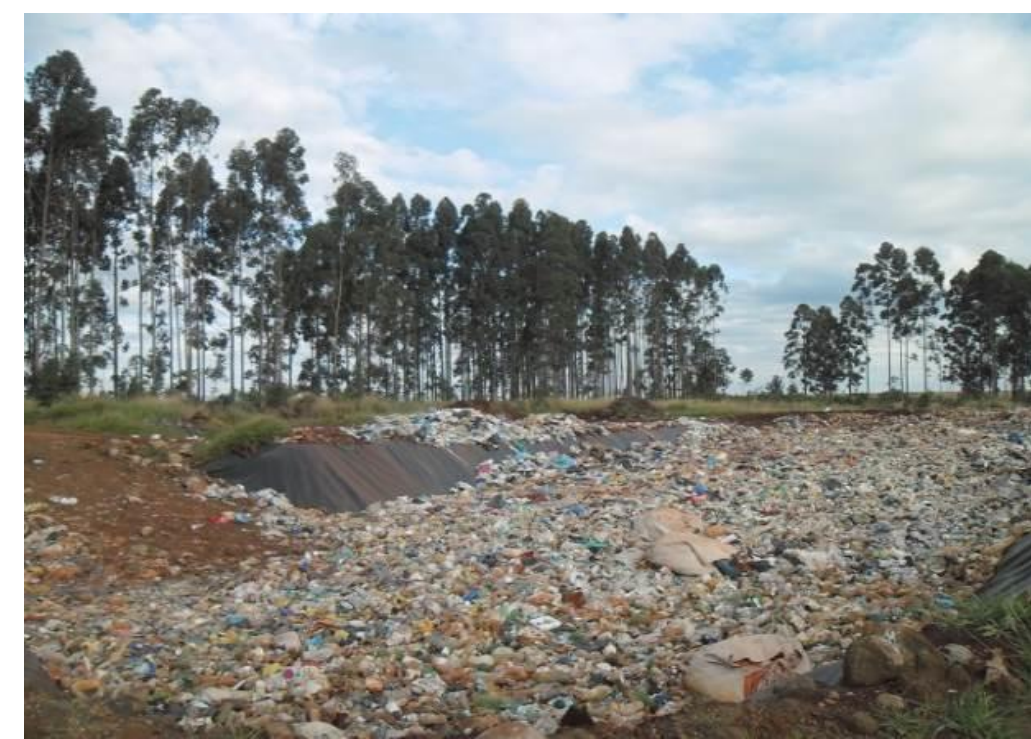

Fonte: Acervo pessoal

Por ser considerado um aterro controlado de pequeno porte, não possui recepção, balança rodoviária, sistema de vigilância 24 horas e nenhum tipo de controle de acesso de veículos ou pessoas no local, bem como o controle da quantidade de materiais disposto no aterro. Fatores que dificultam o planejamento de gestão dos resíduos sólidos gerados no município.

\section{Condições Operacionais}

A Tabela 3 traz o índice de qualidade de aterros de resíduos referente às pontuações das condições operacionais. 
Tabela 3. Índice de qualidade de aterros de resíduos- IQR, pontuação referente. Item: Condições operacionais

\begin{tabular}{|c|c|c|c|}
\hline Subitem & Condições & Pontos & Peso \\
\hline \multirow[t]{2}{*}{ Aspecto geral } & Bom & 4 & \multirow[t]{2}{*}{0} \\
\hline & Ruim & 0 & \\
\hline \multirow[t]{2}{*}{ Ocorrência de lixo descoberto } & Não & 4 & \multirow[t]{2}{*}{0} \\
\hline & Sim & 0 & \\
\hline \multirow[t]{3}{*}{ Recobrimento do lixo } & Adequada & 4 & \multirow[t]{3}{*}{1} \\
\hline & Inadequada & 1 & \\
\hline & Inexistente & 0 & \\
\hline \multirow[t]{2}{*}{ Presença de urubus ou gaivotas } & Não & 1 & \multirow[t]{2}{*}{0} \\
\hline & Sim & 0 & \\
\hline \multirow[t]{2}{*}{ Presença de moscas em grande quantidade } & Não & 2 & \multirow[t]{2}{*}{0} \\
\hline & Sim & 0 & \\
\hline \multirow{2}{*}{ Presença de catadores } & Não & 3 & \multirow[t]{2}{*}{0} \\
\hline & Sim & 0 & \\
\hline \multirow[t]{2}{*}{ Criação de animais (porcos, bois) } & Não & 3 & \multirow[t]{2}{*}{3} \\
\hline & Sim & 0 & \\
\hline \multirow[t]{2}{*}{ Descarga de resíduos de serviço de saúde } & Não & 4 & \multirow[t]{2}{*}{4} \\
\hline & Sim & 0 & \\
\hline \multirow[t]{2}{*}{ Descarga de resíduos industriais } & Não, adequada & 4 & \multirow[t]{2}{*}{4} \\
\hline & $\begin{array}{l}\text { Sim, } \\
\text { inadequada }\end{array}$ & 0 & \\
\hline \multirow{3}{*}{$\begin{array}{l}\text { Funcionamento da drenagem pluvial } \\
\text { definitiva }\end{array}$} & Bom & 2 & \multirow[t]{3}{*}{1} \\
\hline & Regular & 1 & \\
\hline & Inexistente & 0 & \\
\hline \multirow{3}{*}{$\begin{array}{l}\text { Funcionamento da drenagem pluvial } \\
\text { provisória }\end{array}$} & Bom & 2 & \multirow[t]{3}{*}{1} \\
\hline & Regular & 1 & \\
\hline & Inexistente & 0 & \\
\hline \multirow[t]{3}{*}{ Manutenção dos acessos internos } & Boas & 2 & \multirow[t]{3}{*}{1} \\
\hline & Regular & 1 & \\
\hline & Inexistente & 0 & \\
\hline \multicolumn{2}{|l|}{ Subtotal máximo } & 35 & 15 \\
\hline
\end{tabular}

Fonte: CETESB, 2006

O confinamento dos resíduos é feita sem compactação e sem cobertura diária com fina camada de solo para evitar a proliferação de vetores causadores de doença, espalhamento dos resíduos pelo entorno do local. A compactação e aterramento dos resíduos são feitos por uma retroescavadeira em média uma vez por semana, insuficiente em função da quantidade de resíduos descartados diariamente no aterro.

O sistema de cobertura dos resíduos tem por objetivo eliminar a proliferação de vetores, diminuírem a taxa de formação de lixiviados, reduzir odores e evitar a saída do biogás. Portanto, a cobertura deve ser realizada diariamente com fina camada de solo de $10 \mathrm{~cm}$ a $20 \mathrm{~cm}$ e no fechamento da 
trincheira, aproximadamente $60 \mathrm{~cm}$. No entanto, na Figura 8, é possível perceber a quantidade de resíduos dispostos na vala, sem compactação ou cobertura com camada de solo.

Figura 8: Resíduos sem cobertura e com acúmulo d'água

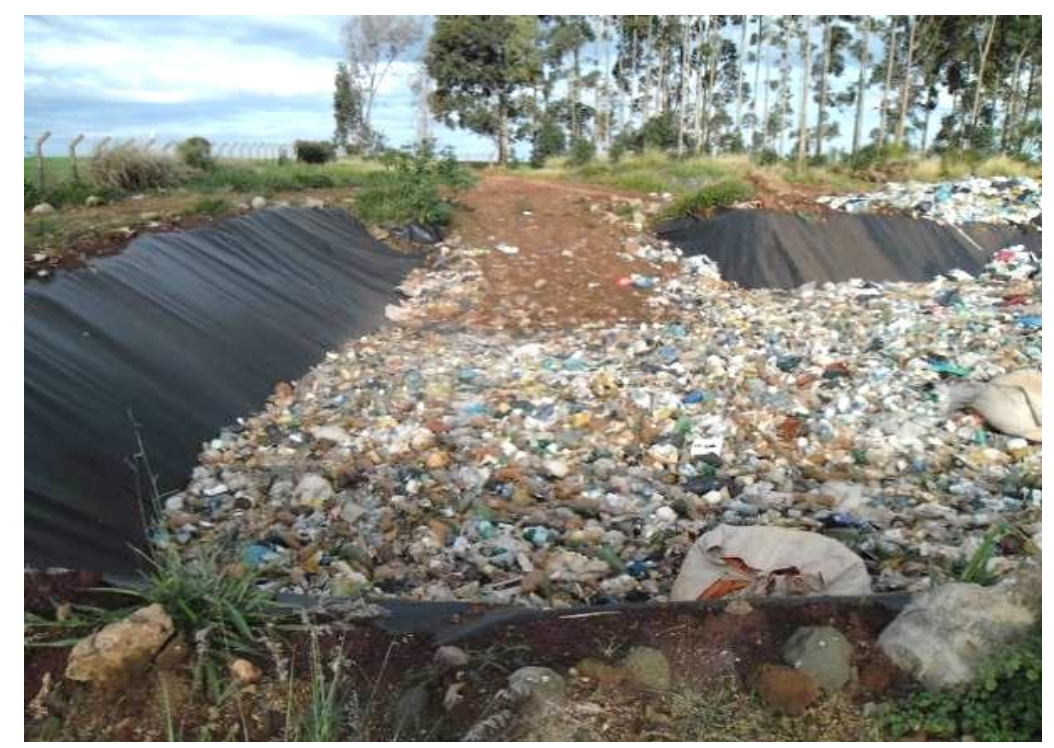

Fonte: Acervo pessoal

Além do aspecto desagradável do local, foram identificadas grande quantidade de materiais recicláveis, matéria orgânica e presença de catadores autônomos no momento da vistoria. A presença de moscas, urubus e garças era constante, principalmente na vala utilizada naquele período para disposição dos resíduos. Tais fatores foram avaliados como ruins e inadequados.

No que diz respeito aos resíduos provenientes de serviço de saúde, estes são coletados e encaminhados à empresa terceirizada, fator positivo que diminui os impactos negativos ao ambiente e a saúde pública.

A manutenção dos acessos internos foi considerada razoável, devido à disposição irregular dos resíduos nas valas dificultando o deslocamento e manuseio de maquinários no local. Tal fato está atrelado com a necessidade de readequação e redirecionamento da área para abertura de novas valas para receber os resíduos. 


\section{Periódica Eletrânica \\ Fórum Ambiental}

da Alta Paulista
Volume 11, Número 09, 2015

Produção e as

Tecnologias Sustentáveis

\section{CONSIDERAÇÕES FINAIS}

Com base no índice de qualidade de aterro de resíduos (IQR-Valas), proposto pela CETESB (2006), aplicado no diagnóstico das condições atuais do aterro do município de Mamborê-PR, as características gerais locacionais são consideradas em condições controladas. As condições operacionais foram consideradas como inadequadas e infraestrutura implantada no local atende parcialmente as estipulações de projeto, sendo classificado como condições inadequadas.

No que diz respeito às condições locacionais, $80 \%$ dos subitens avaliados foram considerados em condições adequadas e $20 \%$ considerados como inadequados ou insuficientes. Todavia, $85 \%$ dos subitens avaliados no item infraestrutura implantada do local foram considerados inadequados ou inexistentes, sendo $15 \%$ em condições adequadas e $66,6 \%$ dos subitens avaliados no item condições operacionais do aterro, foram considerados inadequados ou inexistentes e apenas $33,4 \%$ dos subitens foram considerados em condições adequadas.

$\mathrm{Na}$ soma total da avalição dos critérios dos três subitens, IQR = $(\mathrm{SUB} 1+\mathrm{SUB} 2+\mathrm{SUB} 3) / 10, \mathrm{IQR}=(33+6+15) / 10, \mathrm{IQR}=5,4 . \mathrm{O}$ aterro foi classificado como em condições inadequadas em vários aspectos, totalizando uma pontuação de 5.4, ou seja, abaixo de 6.0. Resultados sujeitos a alterações em função do avaliador e da forma de gestão dos resíduos encaminhados ao aterro em determinados períodos e épocas do ano.

\section{REFERÊNCIAS BIBLIOGRÁFICAS}

ABRELPE. Associação Brasileira de Empresas de Limpeza Pública e Resíduos Especiais. Panorama dos Resíduos Sólidos no Brasil. Ed. 11a, 2013, pg 114. Disponível em: site@abrelpe.org.br. Acesso: 20 de Março de 2015.

Albertin, R. M. E. et al. Avaliação e Diagnóstico do Gerenciamento dos Resíduos Sólidos Urbanos no Município de Cianorte-PR, 2010. Disponível em: http://pluris2010.civil. Acesso em: 25 de Março de 2015.

ABNT- Associação Brasileira de Normas Técnicas. Resíduos Sólidos - Classificação, NBR 10004. São Paulo, 2004.

ABNT- Associação Brasileira de Normas Técnicas. Apresentação de Projetos de Aterros Sanitários de Resíduos Sólidos Urbanos - Procedimentos, Rio de Janeiro, 1984. 


\section{Periódica Eletrônica

Besen, G. R. et al. Resíduos sólidos: vulnerabilidades e perspectivas. In: SALDIVA P. et al. Meio ambiente e saúde: o desafio das metrópoles. São Paulo: Ex Libris, 2010.

Bidone, F. R. A.; Povinelli, J. Conceitos Básicos de Resíduos Sólidos. EESC/USP, São Carlos-SP,1999, $120 \mathrm{pg}$.

CONAMA- Conselho Nacional do Meio Ambiente, Resolução no001/1986. Dispõe Sobre Critérios Básicos. Diretrizes Gerais para o Relatório de Impacto Ambiental (RIMA). Disponível em: http://www.mma.gov.br/port/conama . Acesso em: 27 de Março de. 2015.

CETESB-Companhia Técnica de Saneamento Ambiental. Procedimentos para Implantação de Aterro Sanitário em Valas. S.P: CETESB, 2006. Disponível em: http://www.ambiente.sp.gov.br . Acesso: 02 de Fev. de 2015.

Consoni, A. J.; Peres, C. S.; Castra, A. P. Capitulo II - Origem e Composição do Lixo. In: Lixo Municipal: Manual de Gerenciamento Integrado. São Paulo: IPT/CEMPRE, 3ª Ed, 2010.

EMBRAPA-CNPS. Centro Nacional de Pesquisa de Solos. Sistema brasileiro de classificação de solos.Brasília: Embrapa -SPI, 1999. 412 p.

IBGE-Instituto Brasileiro de Geografia e Estatística. Contagem Populacional: Brasil, Censo 2010. Disponível em: http://geoftp.ibge.gov.br . Acesso em: 18 de Março de 2015.

IPARDES- Instituto Paranaense de Desenvolvimento Econômico e Social. Disponível em http://www.ipardes.gov.br. Acesso em: 10 de Fevereiro de 2015.

PNRS- Lei $n^{\circ}$. 12.305, de 02 de ago. de 2010. Institui a Política Nacional de Resíduos Sólidos. In: Presidência da República Brasileira, Brasília, 2010. Disponível: http://www.planalto.gov.br. Acesso em 18 de março 2015.

PGRS-Plano de Gerenciamento de Resíduos Sólidos- Secretaria de Agricultura e Meio Ambiente de Mamborê-PR, 2009.

Neto, et al. Manual de operação de aterro sanitário em valas / CETESB - São Paulo : CETESB, 2010. Projeto Ambiental Estratégico Lixo Mínimo. Disponível em: http://www.ambiente.sp.gov.br. Acesso em: 10 de Fevereiro de 2014. 